\title{
A protocol for microbiologically safe preparation, storage, and use of autologous serum eye-drops in low-income countries
}

\author{
Francesco Blasetti ${ }^{1}$, Donatella Usai ${ }^{2}$, Salvatore Sotgia ${ }^{3}$, Ciriaco Carru ${ }^{3,4}$, Stefania Zanetti ${ }^{2,4}$, Antonio \\ Pinna $a^{1,4}$ \\ ${ }^{1}$ Section of Ophthalmology, Department of Surgical, Microsurgical, and Medical Sciences, University of Sassari, \\ Sassari, Italy \\ ${ }^{2}$ Section of Experimental and Clinical Microbiology, Department of Biomedical Sciences, University of Sassari, \\ Sassari, Italy \\ ${ }^{3}$ Section of Clinical Biochemistry, Department of Biomedical Sciences University of Sassari, Sassari, Italy \\ ${ }^{4}$ Azienda Ospedaliero-Universitaria di Sassari, Sassari, Italy
}

\begin{abstract}
Introduction: The study aimed to investigate whether the preparation, storage, and use of autologous serum in insulin syringes is microbiologically safe.

Methodology: Blood samples $(10 \mathrm{~mL})$ were obtained from 10 volunteers. After centrifugation, the supernatant serum was removed and distributed in 5 sterile insulin syringes for each sample; syringes were numbered 0 to 4 and labelled with the subject's details. Syringes were immediately transported to the microbiology laboratory and stored in a refrigerator at $+4{ }^{\circ} \mathrm{C}$. The " 0 " labelled syringes were separated from the others and $100 \mu \mathrm{l}$ of serum from each syringe was immediately seeded on chocolate and Sabouraud agar plates, which were incubated aerobically at $37^{\circ} \mathrm{C}$ for 96 hours to detect any bacterial and/or fungal contamination. In the next 4 days, the same procedure was repeated for the remaining syringes: on day 1 , the " 1 " labelled syringes were analyzed; on day 2 , the " 2 " labelled ones, and so on. In a second experiment, blood samples were obtained from 5 different volunteers. The same procedure as above was followed, but each syringe was used for repeated cultures at 2-hour intervals, for a total of 12 cultures/day. The needle was removed and replaced for each inoculation and the syringes were stored in the refrigerator after use.

Results: Under these experimental conditions, none of the cultures showed microbial growth.

Conclusions: Results suggest that, under the protocol described, preparation, storage and use of undiluted autologous serum in insulin syringes is inexpensive, fast, and microbiologically safe. This is of great importance for low-income countries.
\end{abstract}

Key words: autologous serum; preparation; storage; administration; microbiological investigation.

J Infect Dev Ctries 2015; 9(1):055-059. doi:10.3855/jidc.4733

(Received 20 January 2014 - Accepted 08 August 2014)

Copyright ( 2015 Blasetti et al. This is an open-access article distributed under the Creative Commons Attribution License, which permits unrestricted use, distribution, and reproduction in any medium, provided the original work is properly cited.

\section{Introduction}

Eye-drops made from autologous serum (AS) have been reported to be effective in the management of ocular surface disorders, such as persistent epithelial defects and severe dry eye syndrome, and after ocular surface reconstruction [1-6]. Their beneficial effect on the damaged ocular surface is related to the supply of a series of epitheliotrophic factors [1]. Since AS eyedrops have a high protein content, there is some risk of microbial colonisation. Added preservatives are usually avoided because of their toxicity, which can negatively affect the epitheliotrophic properties of serum. Furthermore, the addition of bacteriostatic agents may not be necessary, because the serum itself has several anti-microbial agents, including lysozyme, complement, and immunoglobulins. The published protocols for the preparation and storage of AS eyedrops are incomplete or vary significantly [1-9]. With the increasing use of AS eye-drops, it is important to have information on their sterility, as ocular surface infections during AS use have been reported [2,3]. Furthermore, the availability of a cheap and rapid method would be of great importance for low-income countries, where ocular surface disorders needing treatment with AS are common.

As far as we know, no report assessing insulin syringe use for AS eye-drop preparation has been previously published. The purpose of this study was to investigate whether the preparation, storage, and use of AS in insulin syringes is microbiologically safe. 


\section{Methodology}

A blood sample was obtained from 10 healthy volunteers (5 males and 5 females) during the same morning. Under aseptic conditions, venesection was performed at the antecubital fossa and $10 \mathrm{~mL}$ of whole blood were collected in sterile vacutainer tubes without additive. The blood was left to clot at $4{ }^{\circ} \mathrm{C}$ for 2 hours before centrifuging at $302 \mathrm{~g}$ for 10 minutes. The supernatant serum was removed in a laminar flow cabinet and distributed in five sterile insulin syringes (0.5 $\mathrm{ml} /$ syringe, $\sim 12-13$ drops) for each sample, numbered 0 to 4 and labelled with the subject's details. The syringes were then re-capped with a new, sterile needle with its cap. Each batch of syringes was put in a separate thermal container at $+4^{\circ} \mathrm{C}$, immediately transported to the microbiology laboratory and stored in a refrigerator at $+4^{\circ} \mathrm{C}$, while the " 0 " labelled syringes were separated from the others. After the needle was removed, $100 \mu \mathrm{l}$ of serum from the " 0 " labelled syringes was immediately seeded on chocolate agar with no antibiotics and Sabouraud agar with chloramphenicol and gentamicin; the remaining serum was discarded. The plates were incubated aerobically at $37^{\circ} \mathrm{C}$ for 96 hours to detect any bacterial and/or fungal contamination. In the next four days, the same procedure was repeated for the remaining syringes: the " 1 " labelled syringes were analyzed on day 1 ; the " 2 " labelled syringes on day 2 , and so on.

In a second experiment, blood samples were obtained from five healthy volunteers. The same procedure as above was followed, but each syringe was used for repeated cultures at 2-hour intervals on the same day, for a total of 12 cultures/day for each syringe. In the next four days, the same procedure was repeated for the remaining syringes. The needle was removed and replaced for each inoculation and the syringes were stored in the refrigerator after use, until they were finally discarded after the last instillation.

In both experiments, one Staphylococcus aureus and one Pseudomonas aeruginosa reference strain

Table 1. Cultures results after repeated seeding of autologous serum on chocolate and Sabouraud agar plates at 2-hour intervals.

\begin{tabular}{|c|c|c|c|c|c|c|}
\hline Sample & Time & $\begin{array}{c}\text { Day 0 } \\
\text { (syringes 0) } \\
\end{array}$ & $\begin{array}{c}\text { Day 1 } \\
\text { (syringes 1) }\end{array}$ & $\begin{array}{c}\text { Day } 2 \\
\text { (syringes 2) }\end{array}$ & $\begin{array}{c}\text { Day } 3 \\
\text { (syringes 3) }\end{array}$ & $\begin{array}{c}\text { Day } 4 \\
\text { (syringes 4) }\end{array}$ \\
\hline \multirow{6}{*}{$\mathbf{A}$} & baseline & no growth & no growth & no growth & no growth & no growth \\
\hline & $2 \mathrm{~h}$ & no growth & no growth & no growth & no growth & no growth \\
\hline & $4 \mathrm{~h}$ & no growth & no growth & no growth & no growth & no growth \\
\hline & $6 \mathrm{~h}$ & no growth & no growth & no growth & no growth & no growth \\
\hline & $8 \mathrm{~h}$ & no growth & no growth & no growth & no growth & no growth \\
\hline & $10 \mathrm{~h}$ & no growth & no growth & no growth & no growth & no growth \\
\hline \multirow{6}{*}{ B } & baseline & no growth & no growth & no growth & no growth & no growth \\
\hline & $2 \mathrm{~h}$ & no growth & no growth & no growth & no growth & no growth \\
\hline & $4 \mathrm{~h}$ & no growth & no growth & no growth & no growth & no growth \\
\hline & $6 \mathrm{~h}$ & no growth & no growth & no growth & no growth & no growth \\
\hline & $8 \mathrm{~h}$ & no growth & no growth & no growth & no growth & no growth \\
\hline & $10 \mathrm{~h}$ & no growth & no growth & no growth & no growth & no growth \\
\hline \multirow{6}{*}{$\mathrm{C}$} & baseline & no growth & no growth & no growth & no growth & no growth \\
\hline & $2 \mathrm{~h}$ & no growth & no growth & no growth & no growth & no growth \\
\hline & $4 \mathrm{~h}$ & no growth & no growth & no growth & no growth & no growth \\
\hline & $6 \mathrm{~h}$ & no growth & no growth & no growth & no growth & no growth \\
\hline & $8 \mathrm{~h}$ & no growth & no growth & no growth & no growth & no growth \\
\hline & $10 \mathrm{~h}$ & no growth & no growth & no growth & no growth & no growth \\
\hline \multirow{6}{*}{ D } & baseline & no growth & no growth & no growth & no growth & no growth \\
\hline & $2 \mathrm{~h}$ & no growth & no growth & no growth & no growth & no growth \\
\hline & $4 \mathrm{~h}$ & no growth & no growth & no growth & no growth & no growth \\
\hline & $6 \mathrm{~h}$ & no growth & no growth & no growth & no growth & no growth \\
\hline & $8 \mathrm{~h}$ & no growth & no growth & no growth & no growth & no growth \\
\hline & $10 \mathrm{~h}$ & no growth & no growth & no growth & no growth & no growth \\
\hline \multirow{6}{*}{$\mathbf{E}$} & baseline & no growth & no growth & no growth & no growth & no growth \\
\hline & $2 \mathrm{~h}$ & no growth & no growth & no growth & no growth & no growth \\
\hline & $4 \mathrm{~h}$ & no growth & no growth & no growth & no growth & no growth \\
\hline & $6 \mathrm{~h}$ & no growth & no growth & no growth & no growth & no growth \\
\hline & $8 \mathrm{~h}$ & no growth & no growth & no growth & no growth & no growth \\
\hline & $10 \mathrm{~h}$ & no growth & no growth & no growth & no growth & no growth \\
\hline
\end{tabular}


obtained from the American Type Culture Collection (ATCC 43300 and ATCC 27853, respectively; ATCC, Manassas, VA) and one clinical isolate of Candida albicans were used as positive controls. Sterile phosphate buffered saline solution (PBSS) was used as negative control. $0.5 \%$ McFarland standard suspensions $\left[10^{8}\right.$ colony-forming units $\left.(\mathrm{CFU}) / \mathrm{mL}\right]$ of $S$. aureus, $P$. aeruginosa, and $C$. albicans were prepared. Twenty $\mu 1$ of each suspension and $20 \mu \mathrm{l}$ of sterile PBS were plated on chocolate agar and Sabouraud agar with antibiotics concurrently with the serum cultures.

Approval from the Ethics Committee/Institutional Review Board of the Department of Surgical, Microsurgical, and Medical Sciences, University of Sassari, Sassari, Italy, was obtained and the study was conducted in complete accord with the principles of the Declaration of Helsinki. Each participant received detailed information and provided written informed consent before inclusion.

\section{Results}

In the first assay, 50 serum syringes were prepared (5 syringes from each blood sample). A total of 100 cultures (50 on chocolate agar and 50 on Sabouraud agar with chloramphenicol and gentamicin) in 5 days (20 cultures/per day) were performed. Under the conditions used in this experiment, none of the chocolate and Sabouraud agar plates seeded with undiluted serum showed any microbial growth after aerobic incubation at $37^{\circ} \mathrm{C}$ for 96 hours.

In the second experiment, 30 serum syringes were prepared (6 syringes from each blood sample). For each blood sample, one syringe per day was used. Repeated undiluted serum cultures were performed at 2-hour intervals, for a total of 12 cultures/day per syringe ( 6 on chocolate agar and 6 on Sabouraud agar with antibiotics) for a total of five days. On the whole, 300 cultures in 5 days (60 cultures per day) were obtained. In this case too, all cultures yielded no microbial growth (Table 1).

In both experiments, all the chocolate agar plates seeded with $S$. aureus and $P$. aeruginosa and all the Sabouraud agar plates seeded with $C$. albicans (positive controls) showed microbial growth, whereas no growth was observed in the corresponding plates inoculated with sterile PBSS (negative control).

\section{Discussion}

AS eye-drops have been used for the treatment of ocular surface disorders, such as Sjögren syndromeand graft vs host disease (GvHD)-related keratoconjunctivitis sicca, superior limbal keratoconjunctivitis, recurrent erosion syndrome, persistent epithelial defects resulting from rheumatoid arthritis, neurotrophic keratopathy, or dry eye, as well as an adjunctive treatment in ocular surface reconstruction following Stevens-Johnson syndrome, toxic epidermal necrolysis (TEN), and cicatricial pemphigoid [1-6].

Serum is the fluid component of the full blood that remains after clotting. It contains a large variety of growth factors, including epidermal growth factor (EGF) and transforming growth factor-beta (TGFbeta), immunoglobulins, and vitamins, some in higher concentrations than in natural tears [1]. The growth and migration-promoting effects of serum on human corneal epithelial cells are well known and its therapeutic effect on the damaged ocular surface is thought to be related to the supply of a series of epitheliotrophic factors [4-10]. In the ophthalmic literature, there are a number of protocols for preparation and storage of AS eye-drops, which vary considerably from each other [1-9]. While it is obvious that serum from various patients will not be identical, other factors, including centrifugation and addition of diluents and/or preservatives or antibiotics, may significantly affect its biochemical, immunological, and epitheliotrophic properties, thus reducing its beneficial effect on the damaged ocular surface [1].

The frequency of administration of AS eye-drops has not been standardized so far. In different studies, it ranged from as often as $1 / 4$ hourly to 3 times daily [ 1 6]. Serum is usually instilled as a preservative-free, autologous product, thus lacking antigenicity. The addition of preservatives or antibiotics is usually avoided, because they can negatively affect some of the beneficial effects of AS and worsen the ocular surface damage. On the other hand, even though the serum itself has some anti-microbial properties due to the presence of lysozyme, complement, and immunoglobulins, the lack of added preservatives or antibiotics may expose it to the risk of microbial contamination during preparation, storage, and use. Repeated administration of preservative-free AS eyedrops from the same container with refrigerator storage between applications may increase the risk of microbial contamination, especially if the container is used for a prolonged period of time. As a result, some authors strongly recommend to avoid using the same 
container for more than a week or, preferably, replacing it every day $[1,7,11,12]$.

In a previous study, Sauer et al. assessed the contamination of AS eye-drops containers in a hospital setting [8]. These authors failed to find any contamination in the samples analyzed on the day of preparation and in the eye drops tested four days later; however, they found that three $(7.5 \%)$ out of 40 containers were contaminated with Staphylococcus epidermidis after a week's use. Similarly, Garcia Jimenez et al. [13] reported no contamination of AS containers tested on the day of preparation, but disclosed contamination rates of approximately $30 \%$ in containers from home-treated patients after five days of use. In another hospital-based survey, Lagnado et al. [7] observed bacterial growth in $13(8.8 \%)$ out of 134 cultures from AS samples, with $S$. epidermidis as the most common isolate $(84.6 \%)$. Furthermore, in a study by Leite et al. [14], microbiological analysis revealed that six out of 11 AS samples were contaminated after 30 days of use, with Klebsiella pneumoniae and Streptococcus viridans as the predominant isolates. More recently, López-García and García-Lozano [9] reported that only one (2.1\%) out of 48 AS containers with an adapted sterilizing filter (ABAK, Théa, Clermont-Ferrand, France) resulted contaminated with $S$. epidermidis after 1 month of treatment, whereas the contamination rate among 128 conventional AS containers was $28.9 \%$ after 7 days of treatment.

In agreement with other studies [7-9], we failed to find any contamination in samples analyzed immediately after preparation of the serum eye-drops or during the follow-up of samples kept in the refrigerator at $4^{\circ} \mathrm{C}$ for $1-5$ days. The results of our second experiment on repeated AS instillations and culturing at 2-hour intervals confirm that contamination rarely occurs during the handling and storage of serum eye-drops, if they are done correctly. Time of use and incorrect container handling by patients or personnel responsible for AS administration are the main factors involved in microbial contamination of AS [7-9]. If contamination of correctly used AS eye-drops is uncommon [7-9], infectious complications related to AS use are even rarer [1], probably because in most cases the antimicrobial agents contained in the serum, along with the concomitant use of topical antibiotics, could overcome an infection in its initial phase and prevent the development of true conjunctivitis and/or keratitis.

\section{Conclusion}

The results of this study suggest that, under the protocol described, preparation and storage of undiluted AS in insulin syringes is inexpensive, fast, and microbiologically safe, at least for the first five days after preparation and for a maximum of six instillations a day. Thus, this protocol may be of great importance in low-income countries, where ocular surface disorders needing treatment with AS are common. Even though, in the clinical setting, repeated use of eye-drops from the same container may increase the risk of bacterial and fungal contamination, this risk is expected to be minimal, if the container is stored in a refrigerator at $4^{\circ} \mathrm{C}$ between applications, handled correctly, and discarded 8 hours after the first use.

\section{Acknowledgements}

This research was in part funded by a grant from Fondazione Banco di Sardegna, Italy.

\section{Authors' Note}

This manuscript was in part presented as a Scientific Poster at the 20th annual scientific meeting of the Medical Contact Lens \& Ocular Association (MCLOSA), London (U.K.), 29th November 2013.

\section{References}

1. Geerling G., MacLennan S, Hartwig D (2004) Autologous serum eye drops for ocular surface disorders. Br J Ophthalmol 88: $1467-1474$.

2. Tananuvat N, Daniell M, Sullivan LJ, Yi Q, McKelvie P, McCarty DJ, Taylor HR (2001) Controlled study of the use of autologous serum in dry eye patients. Cornea 20: 802-806.

3. Poon AC, Geerling G, Dart JK, Fraenkel GE, Daniels JT (2001) Autologous serum eyedrops for dry eyes and epithelial defects: clinical and in vitro toxicity studies. Br J Ophthalmol 85: 1188-1197.

4. Tsubota K, Goto E, Shimmura S, Shimazaki J (1999) Treatment of persistent corneal epithelial defect by autologous serum application. Ophthalmology 106: 19841989.

5. Tsubota K, Goto E, Fujita H, Ono M, Inoue H, Saito I, Shimmura S (1999) Treatment of dry eye by autologous serum application in Sjögren's syndrome. Br J Ophthalmol 83: 390-395.

6. Tsubota K, Satake Y, Ohyama M, Toda I, Takano Y, Ono M, Shinozaki N, Shimazaki J (1996) Surgical reconstruction of the ocular surface in advanced ocular cicatricial pemphigoid and Stevens-Johnson syndrome. Am J Ophthalmol 122: 3852.

7. Lagnado R, King AJ, Donald F, Dua HS (2004) A protocol for low contamination risk of autologous serum drops in the management of ocular surface disorders. Br J Ophthalmol 88: 464-465. 
8. Sauer R, Blüthner K, Seitz B (2004) Sterility of nonpreserved autologous serum drops for treatment of persistent corneal epithelial defects [in German]. Ophthalmologe 101: 705-709.

9. López-García JS, García-Lozano I (2012) Use of containers with sterilizing filter in autologous serum eyedrops. Ophthalmology 119: 2225-2230.

10. Geerling G., Daniels JT, Dart JK, Cree IA, Khaw PT (2001) Toxicity of natural tear substitutes in a fully defined culture model of human corneal epithelial cells. Invest Ophthalmol Vis Sci 42: 948-956.

11. Bradley JC, Simoni J, Bradley RH, McCartney DL, Brown SM (2009) Time- and temperature-dependent stability of growth factor peptides in human autologous serum eye drops. Cornea 28: 200-205.

12. Sitaramamma T, Shivaji S, Rao GN (1998) Effect of storage on protein concentration of tear samples. Curr Eye Res 17: $1027-1035$.

13. Garcia Jimenez V, Veiga Villaverde B, Baamonde Arbaiza B, Cahue Carpintero I, Celemín Viñuela ML, Simó Martínez RM (2003) The elaboration, use and evaluation of eye-drops with autologous serum in corneal lesions [in Spanish]. Farm Hosp 27: 21-25.

14. Leite SC, de Castro RS, Alves M, Cunha DA, Correa ME, da Silveira LA Vigorito AC, de Souza CA, Rocha EM (2006) Risk factors and characteristics of ocular complications, and efficacy of autologous serum tears after haematopoietic progenitor cell transplantation. Bone Marrow Transplant 38: $223-227$.

\section{Corresponding author}

Dr. Antonio Pinna

Section of Ophthalmology, Department of Surgical, Microsurgical, and Medical Sciences, University of Sassari, Viale San Pietro 43

A, 07100 Sassari, Italy.

Phone: +39079228251

Fax: +39079228484

Email: apinna@uniss.it

Conflict of interests: No conflict of interests is declared. 